\title{
Developing a Pressure Control Valve for Air Extraction Cupping Device
}

\author{
Jae Yong Lee ${ }^{1}$, Dong Wook Shim ${ }^{1}$, Soo Kwang $\mathrm{An}^{1}$, \\ Eun Seok Kim ${ }^{2,3}$, Byung Ryul Lee, ${ }^{2,3}$, Gi Young Yang ${ }^{2,3}$ \\ ${ }^{1}$ School of Korean Medicine, Pusan National University, \\ ${ }^{2}$ Division of Clinical Medicine, School of Korean Medicine, Pusan National University, \\ ${ }^{3}$ Department of Acupuncture and Moxibustion Medicine, Pusan National University Korean Medicine Hospital
}

\section{부항 장치용 압력 제어 밸브 개발}

\author{
이재용 ${ }^{1(1)} \cdot$ 심동욱 $^{1(1)} \cdot$ 안수광 $^{1(1)} \cdot$ 김은석 ${ }^{2,3(1)} \cdot$ 이병렬 ${ }^{2,3(1)} \cdot$ 양기영 ${ }^{2,3(1)}$ \\ ${ }^{1}$ 부산대학교 한의학전문대학원, ${ }^{2}$ 부산대학교 한의학전문대학원 임상의학3교실, ${ }^{3}$ 부산대학교한방병원 침구의학과
}

\begin{abstract}
Objectives: This study aimed to develop a cupping pressure control valve for limiting maximum negative pressure while achieving clinical therapeutic outcomes to minimize side effects induced by excessive negative pressure of air extraction cupping devices. Methods : To determine the clinical necessity and suitability of the cupping pressure control valve, this study was designed to measure the change in pressure with or without the valve using both a manual and an electric suction pump. Results: While the maximum pressure was limited by the pressure control valve, the pressure did not increase above a certain level regardless of the type of manual or electric pump. Conclusions : This study will contribute to the development of a safer and more effective base technology for cupping treatment in oriental medicine.
\end{abstract}

Key words : pressure control valve, cupping, maximum negative pressure

\section{Introduction}

Cupping therapy is a treatment method in which cups are placed on the skin to remove air from the inside, and the negative pressure generated by the cup is used to discharge various elements from the body to the outside of the body ${ }^{1)}$. Fire cupping using glass is used to remove stasis or remove climatic lesions based on oriental medicine principles, whereas silicone cupping is used to treat myofascial synd- rome from a modern soft tissue perspective ${ }^{2)}$.

In a questionnaire conducted by oriental doctors in 2008, more than $90 \%$ of the 2001 respondents answered that they were using cupping treatment in the clinical setting, and the main focuses were musculoskeletal system, stroke, paralysis, and internal diseases in that order. Of all the respondents, 1836 (94.4\%) used a manual cupping pump ${ }^{3)}$.

Analysing 27 studies on cupping at home and abroad revealed that, although several cupping procedures are being

Received November 11, 2021, Revised December 21, 2021, Accepted December 21, 2021

Corresponding author: Gi Young Yang

Division of Clinical Medicine, School of Korean Medicine, Pusan National University, 20 Geumo-ro, Mulgeum-eup, Yangsan 50612, Korea

Tel: +82-55-360-5963, Fax: +82-55-360-5509, E-mail: ygy@pnu.edu

This work was supported by the National Research Foundation of Korea grant funded by the Korean government (no.: NRF2019R1F1A1051568).

(C) This is an open access article distributed under the terms of the Creative Commons Attribution Non-Commercial License (http://creativecommons.org/licenses/ by-nc/4.0) which permits unrestricted non-commercial use, distribution, and reproduction in any medium, provided the original work is properly cited. 
used, they have not been standardized. Each operator worked with different cupping tools, maximum negative pressure, and cup size or volume. In addition, even in research papers, there were many cases where the conditions for cupping were not recorded in detail ${ }^{4}$.

Although there is no clinical evaluation of the effective level at which pressure should be maintained ${ }^{5}$, it is generally recommended to maintain the negative pressure at 300 $400 \mathrm{mmHg}$ for 20 30 s and gradually increase the pressure ${ }^{1)}$. However, in clinical practice, it is difficult to directly measure negative pressure. In the 2008 survey, 974 (53.1\%) of 1836 people who answered that they used a suction pump replied they do a three-time pump ${ }^{3}$.

During cupping, if negative pressure is excessive, the following may occur: a pigmentation reaction that changes the skin color, a coagulation reaction, a purpura reaction, and a blister reaction that causes blisters on the skin $^{6}$. Blisters that occur after cupping are more likely to happen if the pressure in the treatment area is high. In addition, the higher the temperature, the easier it is to form blisters even at the same pressure ${ }^{7}$.

Accordingly, an experiment was conducted on the suction pump valve nozzle, which was developed to control the negative pressure and to minimize the side effects while achieving clinical therapeutic outcomes by limiting the maximum negative pressure not excessively. Through this experiment, we tried to examine the suitability of the new suction pump valve nozzle to several air-discharge cupping cups, manual pumps, and electric pumps that are distributed in the market.

\section{Materials and Methods}

\section{Materials}

The pressure control valve includes a body part having an airtight inner space and a pressure adjusting part provided on one side of the body part to adjust the pressure inside the body part. The pressure adjusting part includes an opening that communicates the space inside the body with the outside of the body, and a stopper that blocks the opening.
When the negative pressure formed in the inner space of the body is above a preset level, the stopper is opened so that the inside space of the body communicates with the outside. Through this process, the maximum negative pressure in the internal space of the body is reduced by interlocking with the outside ${ }^{8}$. After connecting the suction pump valve nozzle between the manual or electric cupping pump and the cupping cup, one can limit the maximum value of the pressure formed inside the cupping by tightening or loosening the pressure regulator. 3D printer (Form3, Formlabs, Somerville, USA) and a clear resin (RS-F2-GPCL-04, Formlabs, Somerville, USA) were used to manufacture the suction pump valve nozzle (Fig. 1).

In order to measure the change in pressure, a skin model similar to the skin of the human body was produced. The skin model used in this experiment was made by supplementing the missing parts based on the existing $3 \mathrm{~mm}$ thick silicon plate model. $20 \mathrm{~mm}$ nitrile-butadiene rubber (NBR) was added below the existing $3 \mathrm{~mm}$ silicone plate to mitigate the impact generated during the cupping attachment process. Acrylic $(360 \times 360 \times 10 \mathrm{~mm})$ was added above and below the silicone plate and NBR to enhance the stability of the skin model during the measurement process. The pressure change during the cupping was measured by making a hole in the combined skin model and connecting it with a digital pressure gauge (Tpi665, SUMMIT, Korea) using a $7 \mathrm{~mm}$ outer diameter pipe and a silicone tube (inner diameter $5.84 \mathrm{~mm}$, outer diameter $9.98 \mathrm{~mm}$ ) on the bottom. Adhesive (SUPER XG, CEMEDINE, Japan) was used to maintain the airtightness of the skin model and silicone tube, cupping and silicone

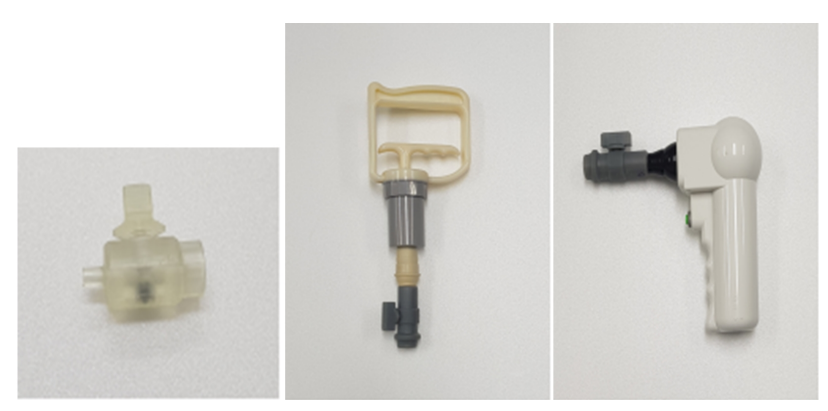

Fig. 1. Valve-controlled suction pump nozzle and its application. 
tube (Fig. 2).

This experiment was conducted using air-discharge type cupping cups, and a total of six commercially available cups obtained from three Korean companies (Hansol, Dongbang, Daekun) and three Chinese types (Jingong, Jinkang, Yifang) were used. For the size types of Buhang, No. 1, 2, and 3 of Korean products and No. 2, 3, and 4 of Chinese products were used. The volume of each cup is shown in Table 1, and it is classified into L (Large), M (Medium), and S (Small) for convenience. The volume of cupping was obtained as an average value through 5 measurements, and 95\% ethanol was used for the measurement. Also, for convenience, the company name is classified into A, B, C, D, E, F in the order of Fig. 3.

Three types of manual suction pumps (Hansol, Dongbang, Daekun) and six types of electric suction pumps were used to pump the air exhaust type cupping used in the experiment (Fig. 4, 5). The six types of electric suction pumps are Tornado Pro (Seasang Medical, Daegu, Korea), Hansol (Hansol Medical Co., Paju, Korea), Airone (Goodpl, Gangwon, Korea), Medishield (Green Cross Medical Science Corp. Gyeonggi, Korea), Seoul (Seoul Buhang, Gyeonggi, Korea), ByeongChjeopp (Pingyang Kude Fitness Equipment Factory, Zhejiang, China) each. Electric pumps were classified into A, B, C, D, E, and F in the order of Fig. 5 for convenience.

\section{Methods}

Because temperature and humidity can affect the experimental results, the measurement environment of the laboratory blocked direct sunlight, and maintained a temperature of $25 \pm 5^{\circ} \mathrm{C}$ and a humidity of $40 \pm 10 \%$.

The first experiment was to measure the change in pres- sure and pumping frequency according to the presence or absence of a pressure control valve using the Hansol Manual Pump. First, the cupping device was placed on the skin model and the pressure change was measured using a manual suction pump. According to the number of pumping times, 'strong' was set to three times, 'medium' to two times, and

Table 1. Volumes according to cup type

\begin{tabular}{cccccc}
\hline & Size & Volume $(\mathrm{ml})$ & & Size & Volume $(\mathrm{ml})$ \\
\hline A & S & $44 \pm 0.89$ & D & S & $33.4 \pm 0.49$ \\
& M & $54.6 \pm 0.8$ & & M & $51.4 \pm 0.49$ \\
& L & $71.6 \pm 0.49$ & & L & $76.8 \pm 0.75$ \\
B & S & $47.6 \pm 0.49$ & E & S & $36.6 \pm 0.49$ \\
& M & $59.6 \pm 1.02$ & & M & $56.2 \pm 0.75$ \\
& L & $79.4 \pm 0.8$ & & L & $82 \pm 0.63$ \\
C & S & $47 \pm 0.63$ & F & S & $24 \pm 0.63$ \\
& M & $55.8 \pm 0.4$ & & M & $55.6 \pm 0.49$ \\
& L & $67 \pm 0.89$ & & L & $79.2 \pm 0.75$ \\
\hline
\end{tabular}

Data are presented as mean \pm SD.

AL : Hansol large, AM : Hansol medium, AS : Hansol small, BL : Dongbang large, BM : Dongbang medium, BS : Dongbang small, $\mathrm{CL}$ : Daekun large, CM : Daekun medium, CS : Daekun small, DL : Jingong large, DM : Jingong medium, DS : Jingong small, EL : Jinkang large, EM : Jinkang medium, ES : Jinkang small, FL : Yifang large, FM : Yifang medium, FS : Yifang small.

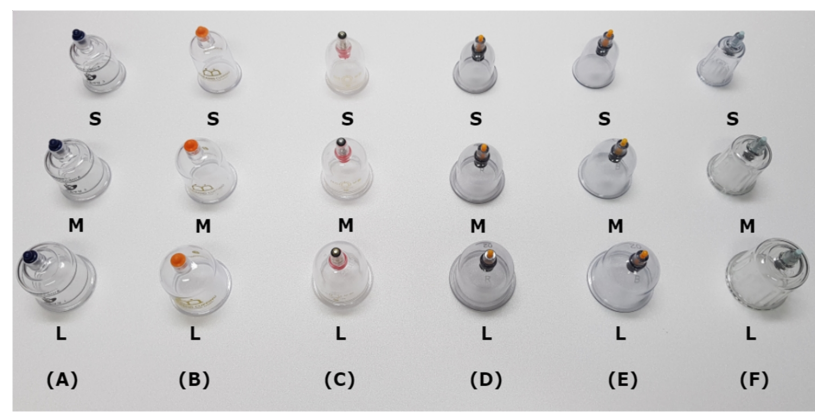

Fig. 3. Types of cups by company.

(A) Hansol, (B) Dongbang, (C) Daekun, (D) Jingong, (E) Jinkang,

(F) Yifang. $\mathrm{L}$ : large, $\mathrm{M}:$ medium, $\mathrm{S}:$ small.
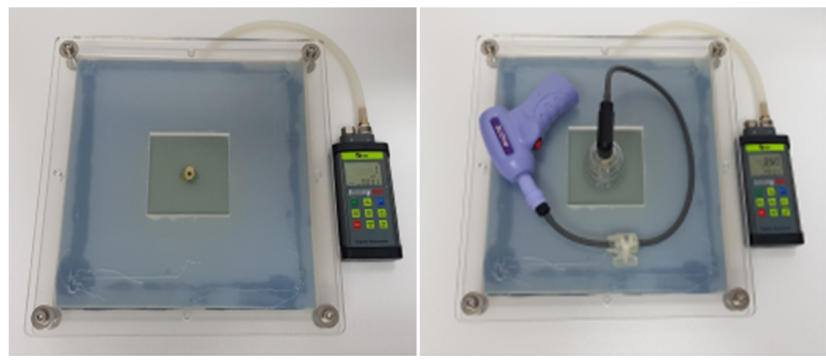

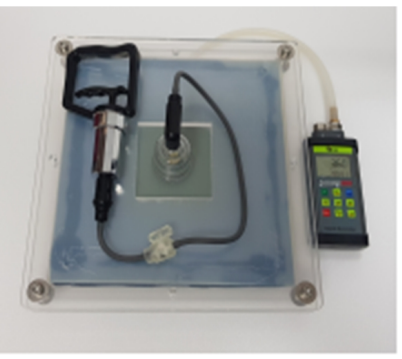

Fig. 2. Skin model with digital manometer and pressure measurement of suction pump. 
'weak' to one according to the number of pumping times. Then, by connecting the pressure control valve, the AL cupping cup was placed on the skin model and the pressure change was measured using a manual suction pump. At this time, by adjusting the pressure control unit, the maximum internal cupping pressure was set similarly to when pumping with high, medium, and low without a valve, and then pumped all four times. Additionally, in order to measure the pressure difference according to the manufacturer of the manual suction

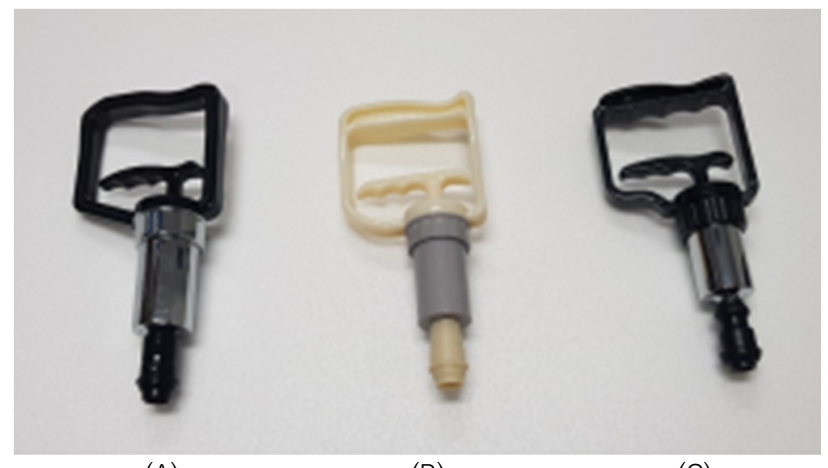

(A)

(B)

(C) pump, the pressure change was measured using the Hansol, Dongbang, and Daekun Manual Pumps for AL, BL, and CL cupping cups with the number of pumping set to one. When pumping, pulling the handle of the suction pump to the end was counted as one pumping number.

The second experiment measured the change in pressure until equilibrium was reached using the A, B, C, D, and $\mathrm{E}$ electric pumps in Fig. 5. After that, the pressure control valve was adjusted so that the maximum internal pressure of the cupping did not exceed $450 \mathrm{mmHg}$ and $350 \mathrm{mmHg}$, and each pressure change value was measured. In addition, the pressure change value was measured for each step using the $\mathrm{F}$ Electric Pump, which has its own pressure control step divided into five.

All pressure data were obtained as an average value through 5 measurements. In all experiments, the internal pressure of the cup was measured in units of 1 second until equilibrium was reached using a digital pressure gauge (Tpi665, SUMMT, Korea).

Fig. 4. Manual suction pumps.

(A) Hansol. (B) Dongbang. (C) Daekun.

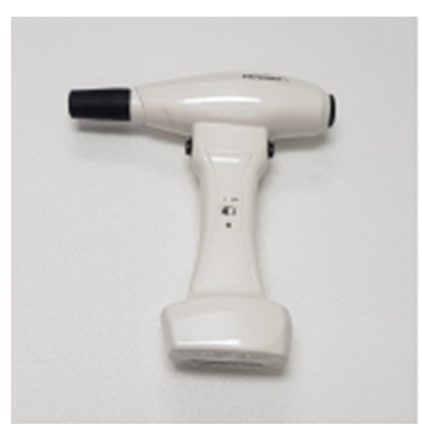

(A)

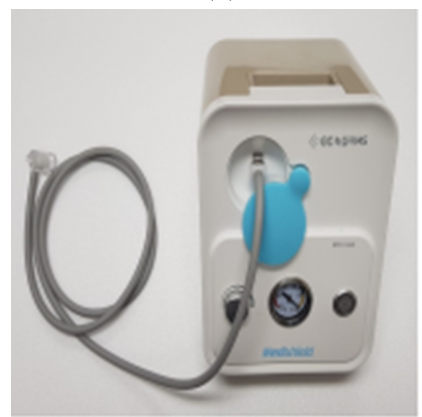

(D)

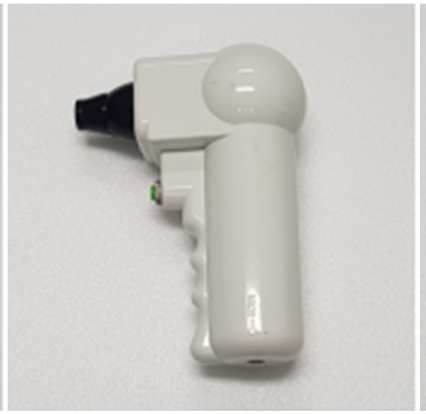

(B)

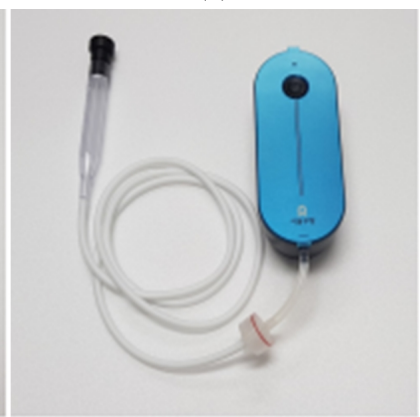

(E)

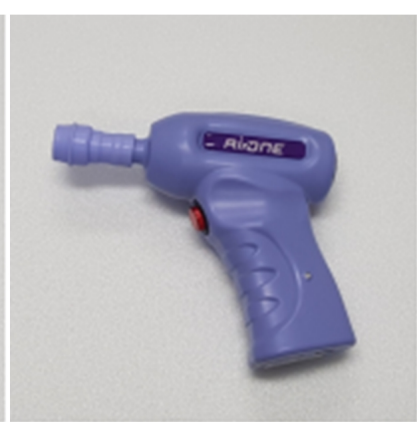

(C)

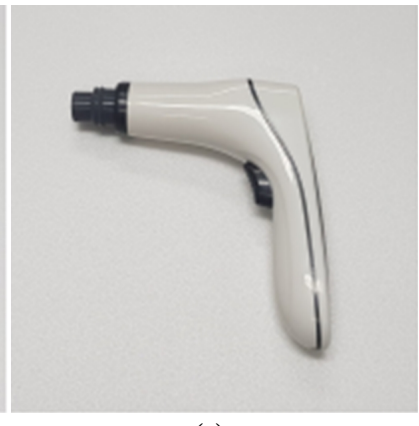

(F)
Fig. 5. Electric suction pumps. (A) Tornado Pro, (B) Hansol, (C) Airone, (D) Medishield, (E) Seoul, (F) ByeongChjeopp. 


\section{Results}

\section{Characteristics according to the presence or absence of a pressure control valve when using a manual suction pump}

It was confirmed that the maximum pressure during cupping was limited by connecting the pressure control valve.

As a result of the experiment, the size distribution of negative pressure was different depending on the cupping cup (Table 2). The reason is that there was a difference in cupping cup volume by size type and manufacturing company. In the case of FL, FM, and FS, the standard deviation of the negative pressure measurement value was large. In addition, the degree of sealing of the air outlet valve of cupping was different for each product. On the other hand, even if the number of pumping was increased while the maximum pressure was limited by the pressure control valve in the $\mathrm{AL}$ cupping cup, the pressure did not increase above a certain level, and uniform negative pressure measurements were shown (Table 3). However, in this case, the number of cupping pumps had to be increased to achieve similar pressure levels as without the valve. In addition, for the AL, BL, and $\mathrm{CL}$ cupping cups, the pressure was measured after pumping once using Hansol, Dongbang, and Daekun Manual Pumps, respectively (Table 4).

Table 3. Pressure levels elicited in AL cup $\mathrm{w} /$ and $\mathrm{w} / \mathrm{o}$ valve

\begin{tabular}{ccccc}
\hline & $\begin{array}{c}\text { Pressure } \\
(\mathrm{mmHg}) \\
\mathrm{w} / \text { valve }\end{array}$ & $\begin{array}{c}\text { Pump } \\
\text { times } \\
\text { w/ valve }\end{array}$ & $\begin{array}{c}\text { Pressure } \\
(\mathrm{mmHg}) \\
\text { w/o valve }\end{array}$ & $\begin{array}{c}\text { Pump } \\
\text { times } \\
\text { w/o valve }\end{array}$ \\
\hline $\mathrm{AL}$ & $370.2 \pm 7.7$ & 4 & $388.7 \pm 6.7$ & 3 \\
& $265.4 \pm 5.3$ & 4 & $294.98 \pm 9.0$ & 2 \\
& $174.8 \pm 2.5$ & 4 & $177.56 \pm 8.3$ & 1 \\
\hline
\end{tabular}

Data are presented as mean \pm SD.

AL : Hansol large, W/ : With, W/O : Without.

Table 4. Pressure levels elicited in AL, BL, CL cup by each manual pump

\begin{tabular}{cccc}
\hline & $\begin{array}{c}\text { Hansol } \\
\text { manual pump }\end{array}$ & $\begin{array}{c}\text { Dongbang } \\
\text { manual pump }\end{array}$ & $\begin{array}{c}\text { Daekun } \\
\text { manual pump }\end{array}$ \\
\hline $\mathrm{AL}$ & $177.6 \pm 8.3$ & $173.1 \pm 4.5$ & $94.8 \pm 6.4$ \\
$\mathrm{BL}$ & $170.6 \pm 4.0$ & $156.7 \pm 3.9$ & $116.0 \pm 2.7$ \\
$\mathrm{CL}$ & $183.4 \pm 3.2$ & $177.1 \pm 7.7$ & $116.8 \pm 7.9$ \\
\hline
\end{tabular}

Data are presented as mean \pm SD.

$\mathrm{AL}$ : Hansol large, $\mathrm{BL}$ : Dongbang large, $\mathrm{CL}$ : Daekun large.

Table 2. Pressure levels elicited in each cup

\begin{tabular}{|c|c|c|c|c|c|c|}
\hline Intensity & $\mathrm{L}$ & Pressure $(\mathrm{mmHg})$ & M & Pressure $(\mathrm{mmHg})$ & $S$ & Pressure $(\mathrm{mmHg})$ \\
\hline $\mathrm{S}$ & $A L$ & $388.7 \pm 6.7$ & AM & $463.6 \pm 4.6$ & AS & $498.2 \pm 2.1$ \\
\hline M & & $294.98 \pm 9.0$ & & $365.9 \pm 3.2$ & & $402.46 \pm 3.2$ \\
\hline W & & $177.56 \pm 8.3$ & & $222.02 \pm 2.2$ & & $249.3 \pm 2.0$ \\
\hline S & $\mathrm{BL}$ & $393.56 \pm 5.9$ & BM & $426.78 \pm 11.0$ & BS & $482.6 \pm 3.1$ \\
\hline$M$ & & $295.18 \pm 4.7$ & & $338.26 \pm 4.1$ & & $387.22 \pm 3.1$ \\
\hline W & & $170.64 \pm 4.0$ & & $199.12 \pm 3.5$ & & $233.68 \pm 2.4$ \\
\hline S & $\mathrm{CL}$ & $418.62 \pm 8.3$ & $\mathrm{CM}$ & $433 \pm 12.5$ & CS & $475.76 \pm 8.5$ \\
\hline$M$ & & $323.24 \pm 6.3$ & & $344.96 \pm 4.6$ & & $381.72 \pm 7.9$ \\
\hline W & & $183.44 \pm 3.2$ & & $210.14 \pm 2.0$ & & $230.9 \pm 6.6$ \\
\hline $\mathrm{S}$ & $\mathrm{DL}$ & $393.36 \pm 5.6$ & DM & $461.82 \pm 7.2$ & DS & $509.3 \pm 8.3$ \\
\hline M & & $300.08 \pm 1.9$ & & $365.84 \pm 2.4$ & & $426.66 \pm 4.2$ \\
\hline W & & $171.64 \pm 3.5$ & & $217.46 \pm 3.8$ & & $268.92 \pm 7.9$ \\
\hline S & EL & $392.16 \pm 7.8$ & EM & $458.92 \pm 4.7$ & ES & $497.06 \pm 9$ \\
\hline$M$ & & $295.34 \pm 2.6$ & & $359.28 \pm 4.5$ & & $392.82 \pm 14.4$ \\
\hline W & & $170.46 \pm 4.5$ & & $214.3 \pm 0.9$ & & $237.38 \pm 12$ \\
\hline S & $\mathrm{FL}$ & $350.96 \pm 22.3$ & $\mathrm{FM}$ & $406.9 \pm 34.3$ & FS & $487.4 \pm 51$ \\
\hline M & & $267.28 \pm 7$ & & $278.82 \pm 35.3$ & & $394.3 \pm 63.1$ \\
\hline W & & $148 \pm 19.3$ & & $186.82 \pm 25.1$ & & $281.36 \pm 32.3$ \\
\hline
\end{tabular}

Data are presented as mean \pm SD.

S : Strong, M : Medium, W : Weak, AL : Hansol large, AM : Hansol medium, AS : Hansol small, BL : Dongbang large, BM : Dongbang medium, BS : Dongbang small, CL : Daekun large, CM : Daekun medium, CS : Daekun small, DL : Jingong large, DM : Jingong medium, DS : Jingong small, EL : Jinkang large, EM : Jinkang medium, ES : Jinkang small, FL : Yifang large, FM : Yifang medium, FS : Yifang small. 
(A) w/o valve

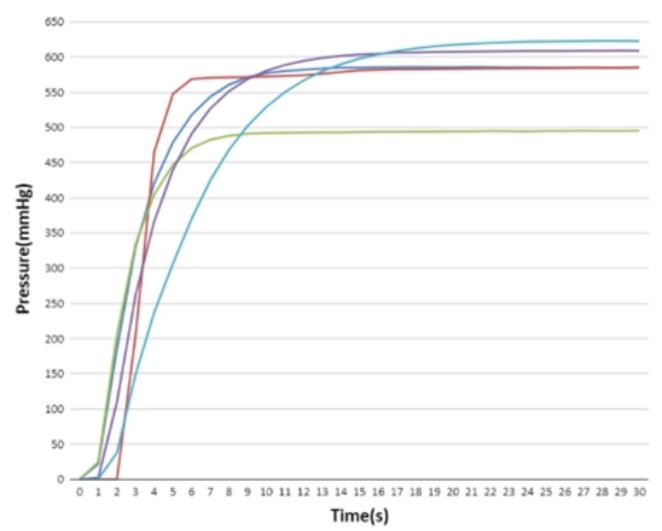

(C) $\mathrm{w} /$ valve with pressure targeted below $350 \mathrm{mmHg}$
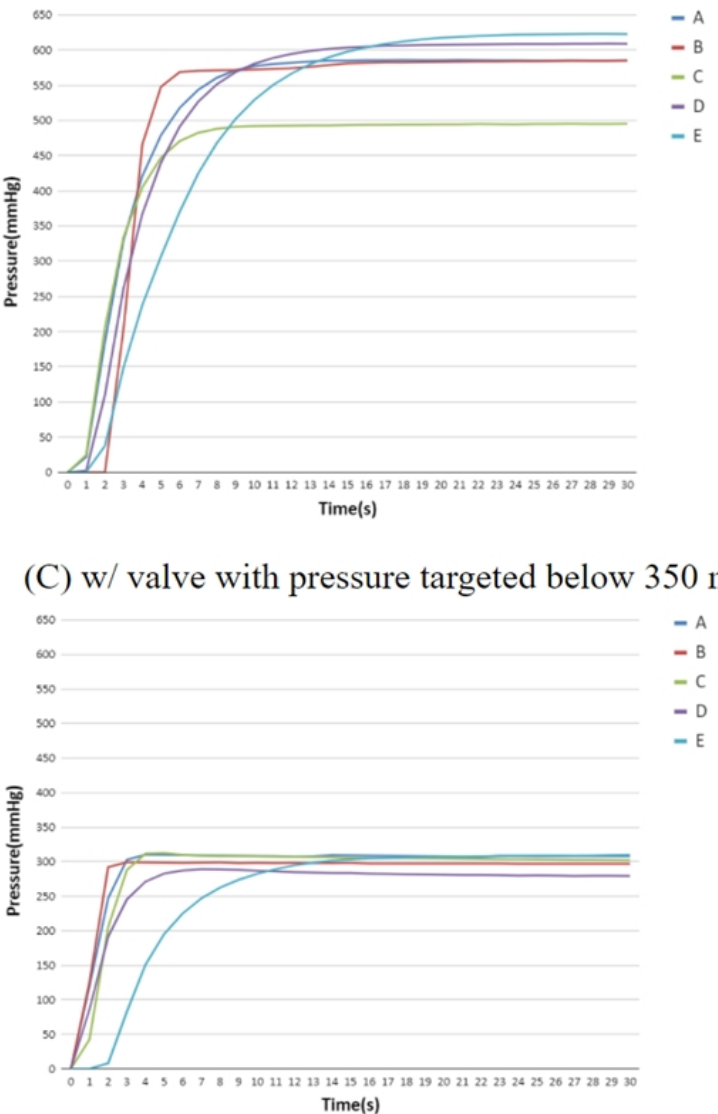

$-B$

$-\mathrm{C}$

$-\mathrm{D}$

$-E$

(B) w/ valve with pressure targeted below $450 \mathrm{mmHg}$

Fig. 6. Pressure levels elicited by each electric pump.

(A) Tornado Pro. (B) Hansol. (C) Airone. (D) Medishield. (E) Seoul. (F) ByeongChjeopp. W/ : With, W/O : Without.

\section{Characteristics according to the presence or absence of a pressure control valve when using an electric suction pump}

It was confirmed that a uniform negative pressure was maintained by connecting the pressure regulating valve.

When using an electric pump (Fig. 6A), the maximum negative pressure was usually reached within five seconds, and the maximum negative pressure value differed depending on the electric pump manufacturer. After setting the maximum value to less than $450 \mathrm{mmHg}$ using the pressure control valve, when the pressure (Fig. 6B) was measured with an electric cupping pump, equilibrium was achieved at the pressure less than the target value. In addition, when the maximum value was set to less than $350 \mathrm{mmHg}$ using the pressure control valve and the pressure (Fig. 6C) was mea-

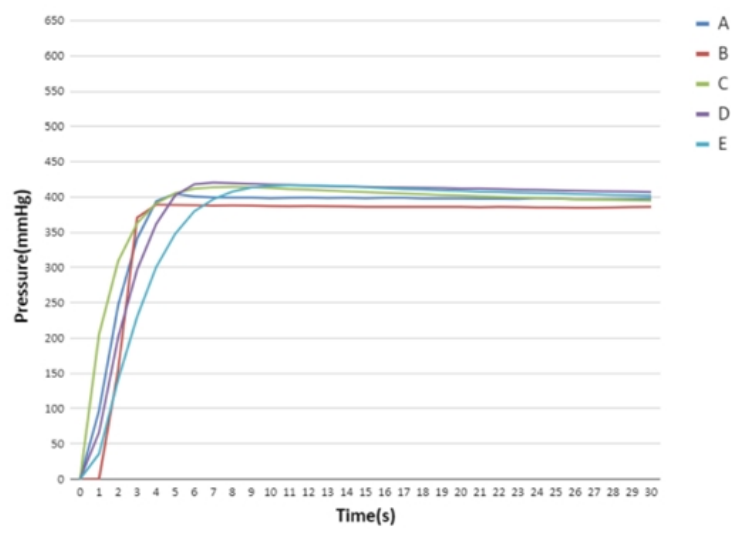

(D) in each pressure regulating stage ( $\mathrm{F}$ electric pump)

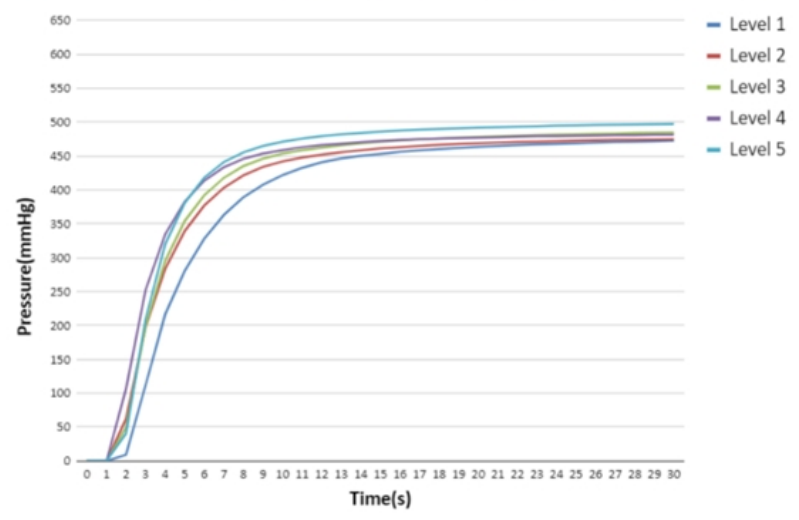

sured with an electric cupping pump, equilibrium was achieved at the pressure less than the target value.

Additionally, the result of measuring the negative pressure using the built-in pressure control function of the F Electric Pump is shown in Fig. 6D. According to the results, there was no significant difference in the maximum pressure value obtained when equilibrium was reached according to the pressure control step, and the speed to reach the equilibrium increased as the step increased.

\section{Discussion}

Being part of a series of studies for standardization of cupping treatment, this study was intended to prove the 
suitability of the device through the development and experimentation of a pressure control valve prototype that can control the operation pressure of cupping and limit the maximum pressure.

The advantage of this pressure control valve is that it is able to control the operation pressure constantly while limiting the maximum internal cupping pressure (Table 3). If the pressure control part above the pressure control valve is adjusted, the maximum pressure can be set as much as the user wants. According to a questionnaire conducted by oriental doctors in 2008, in the case of manual pumps, the procedure was performed according to the number of pulls rather than the specific target value of pressure ${ }^{3)}$. On the other hand, in the case of electric pumps, since the suction power varies from company to company, the operator had to arbitrarily stop suction at an appropriate pressure level, which made it difficult to control the pressure. Therefore, this device can be used as a stabilizer to minimize side effects such as coagulation reaction or blister reaction from cupping with excessive negative pressure ${ }^{7)}$.

However, when a manual suction pump was used, the number of pumping had to be increased in order to obtain a similar negative pressure to the existing one by using a pressure control valve (Table 4). When cupping is performed on a large number of patients in a medical institution, increasing the number of pumps can be a burden in a situation where the operator's fatigue may accumulate with the cupping procedure using a manual suction pump.

On the other hand, when the electric suction pump was used (Fig. 6), it took only about five seconds to reach the maximum pressure, and even when the pressure control valve was connected, there was no burden of additional pumping like a manual suction pump. In terms of valve accuracy, manual pumps lose their accuracy as the pressure goes up and down during the pumping process. On the other hand, the electric pumps showed relatively uniform accuracy because pressure was continuously applied during the pumping process. Hence, it is necessary to apply a pressure regulating valve to electric pumps in medical institutions.

The sudden pressure drop during the cupping causes the recipient to feel strong pain. When the negative pressure in the exhaust pipe reaches $500 \mathrm{mmHg}$, the proportion of air is reduced and the proportion of skin in the exhaust pipe can reach up to $66 \% 9)$. Due to the characteristics of the electric suction pump that quickly reaches the maximum pressure (Fig. 6A), it is necessary to control the maximum pressure.

Among the electric cupping pumps used in the experiment, there were two types of electric cupping pumps capable of regulating the pressure on their own. Medishield (Fig. 5D) has the advantage of being able to control the negative pressure in detail in the range of $50 \mathrm{mmHg} \sim 600 \mathrm{mmHg}$. But it has a large size and a means of connecting a power source other than a rechargeable battery type. So, there was a restriction on the place of use. In the case of the ByeongChjeopp Electric Pump (Fig. 5F), there was only a difference in speed until reaching equilibrium at each stage of pressure control, and there was no substantial difference in the maximum pressure (Fig. 6D).

What needs to be decided for the standardization of cupping procedure is the objectification of the pressure levels and maintenance function that can be applied to manual, electric and disposable cupping cups. In the case of electric cupping machines, there are cases where the strength can be adjusted to strong, medium, or weak, but the strength is not unified for each device ${ }^{10}$. In the case of a manual cupping device, the pressure measurement value (Table 4) was different even if the number of pumping were the same depending on the pump and cupping device. Determining the degree of strong, medium, or weak by the number of pumping times of a manual cupping pump may be problematic because the pressure difference varies greatly depending on the type of pump. Therefore, there is a need for a valve device capable of regulating the pressure. In some Chinese cupping products, the standard deviation (Table 2) of the five pressure measurements was large in some cases. It can be seen that there was a problem in the sealing of the air exhaust valve due to the low quality of the product. The range of negative pressure during cupping was 305.4 401.3 mmHg when using the fire cupping method through glass cupping or 
bamboo cupping ${ }^{11}$. In domestic studies, the maximum negative pressure during cupping was $540 \sim 660 \mathrm{mmHg}$, and in overseas studies, the maximum negative pressure was $420 \mathrm{mmHg}^{\text {() }}$. In the future cupping procedure, a follow-up study on standard procedures and appropriate pressures agreed upon at home and abroad is needed.

In this study, the experiment was conducted on a skin model, not human skin. In accordance with the standards of $\mathrm{K}$ P ISO, traceability was secured to maintain the pressure inside the cupping, but the skin model has a limitation of not being able to represent the actual body hair and pores in the skin. Therefore, if cupping is actually performed on the recipient, the experimental results may vary depending on factors such as age, sex, and skin condition of the recipient. Therefore, it is necessary to prove the effectiveness of the pressure control valve through follow-up studies on various actual human skins.

\section{Conclusion}

The pressure control valve developed through this study can control the operation pressure of cupping as desired, and by limiting the maximum pressure, it can eliminate the skin clotting or blister reactions caused by excessive negative pressure, or reduce the pain of the recipient. It was also confirmed that the maximum pressure level can be adjusted as desired regardless of the type of manual or electric pump. In addition, it was confirmed that the pressure difference due to the difference in the volume of the cupping cup was reduced and the negative pressure was maintained uniformly. This pressure control valve is meaningful in that it has developed a safer and more effective base technology for cupping treatment in oriental medicine. It is hoped that follow-up studies will lead to standardization of cupping procedures.

\section{Acknowledgement}

None.

\section{Funding}

This work was supported by the National Research Foundation of Korea grant funded by the Korean government (no.: NRF2019R1F1A1051568).

\section{Data availability}

The authors can provide upon reasonable request.

\section{Conflicts of interest}

The authors have declared that no conflicts of interest exists.

\section{References}

1. Korean Acupuncture \& Moxibustion Medicine Society. Acupuncture medicine. 4th ed. Seoul : HANMI Medical Publishing Co. 2020 : 119 .

2. Ilkay ZC. Traditional Chinese medicine cupping therapy. 3rd ed. London : Churchill Livingstone. $2014:$ 18-93.

3. Lee BY, Song YK, Lim HH. Literature Investigation Regarding Cupping Therapy and Analysis of Current Professional's Cupping Treatment. J Orient Rehabil Med. 2008 ; 18(2) : 169-91.

4. Kim KW, Lee TW, Lee HL, An SK, Park HS, Choi JW, et al. Pressure Levels in Cupping Therapy: A Systemic Review. J Acupunct Res. 2020 ; 37(1) : 28-34. https://doi.org/10.13045/jar.2019.00339

5. Yi SH, Kim EJ, Shin KH, Nam DW, Kang JW, Lee SD, et al. Study of Mechanical Characteristics of Electric Cupping Apparatus in Korea for Suggestion of its Assessment Guideline. J Korean Acupunct Moxib Soc. 2010 ; 27(1) : 1-10. 
6. The Society of Korean Medicine Rehabilitation. Korean Medicine Rehabilitation. 2nd Ed. Paju : Koonja Publishing Inc. 2005 : $355-9$.

7. Yun HY, Kwon SO, Kim ST, Park HJ, Hahm DH, Lee HJ. The Study of Blister Caused by Cupping Therapy. Korean J Acupunct. 2011 ; 28(3) : 141-50.

8. GY Yang, inventor; Institute for Research \& Industry Cooperation, Pusan National University, assignee. Suction pump valve nozzle and cupping device comprising the same. Korea patent KR 102255605, 2021 May 18. https://doi.org/10.8080/1020180137485.

9. Kim YJ, Kim DH, Yeom SH, Lim BC, Choi YS, Lee GH, et al.
Experimental study on the pressure characteristics in the cupping therapy. The Journal of Korean Acupuncture \& Moxibustion Society. 2008 ; 25(1) : 121-30.

10. Soh MG, Song YK, Lim HH. Comparative Study on Cupping Apparatuses for Medical Use by Mechanical Stability and Functional Test. J Oriental Rehab Med. 2008 ; 18(2) : 157-67.

11. Soo KA, Ku WK, Ha LL, Tae WL, Eun SK, Byung RL, et al. An Experimental Study on the Pressure Range of Fire Cupping Method. J Acupunct Res. 2021 ; 38(3) : 41-6. https://doi.org/ 10.13045/jar.2021.00080 